\title{
Dichloroacetate induces apoptosis and cell-cycle arrest in colorectal cancer cells
}

\author{
BM Madhok ${ }^{*, 1}$, S Yeluri', SL Perry', TA Hughes ${ }^{2}$ and DG Jayne' \\ 'Section of Translational Anaesthesia \& Surgery, University of Leeds, Level 7 Clinical Sciences Building, St. James's University Hospital, Leeds, UK; \\ ${ }^{2}$ Leeds Institute of Molecular Medicine, University of Leeds, St. James's University Hospital, Leeds, UK
}

BACKGROUND: Cancer cells are highly dependent on glycolysis. Our aim was to determine if switching metabolism from glycolysis towards mitochondrial respiration would reduce growth preferentially in colorectal cancer cells over normal cells, and to examine the underlying mechanisms.

METHODS: Representative colorectal cancer and non-cancerous cell lines were treated with dichloroacetate (DCA), an inhibitor of pyruvate dehydrogenase kinase.

RESULTS: Dichloroacetate $(20 \mathrm{~mm})$ did not reduce growth of non-cancerous cells but caused significant decrease in cancer cell proliferation $\left(P=0.009\right.$ ), which was associated with apoptosis and $G_{2}$ phase cell-cycle arrest. The largest apoptotic effect was evident in metastatic LoVo cells, in which DCA induced up to a ten-fold increase in apoptotic cell counts after 48 h. The most striking $\mathrm{G}_{2}$ arrest was evident in well-differentiated HT29 cells, in which DCA caused an eight-fold increase in cells in $\mathrm{G}_{2}$ phase after 48 h. Dichloroacetate reduced lactate levels in growth media and induced dephosphorylation of El $\alpha$ subunit of pyruvate dehydrogenase complex in all cell lines, but the intrinsic mitochondrial membrane potential was reduced in only cancer cells $(P=0.04)$. CONCLUSIONS: Pyruvate dehydrogenase kinase inhibition attenuates glycolysis and facilitates mitochondrial oxidative phosphorylation, leading to reduced growth of colorectal cancer cells but not of non-cancerous cells.

British Journal of Cancer (2010) I 02, 1746- 1752. doi:I0.1038/sj.bjc.660570I www.bjcancer.com

Published online 18 May 2010

(c) 2010 Cancer Research UK

Keywords: dichloroacetate; colorectal cancer; pyruvate dehydrogenase; pyruvate dehydrogenase kinase

Colorectal cancer is the third most common cancer in the world and the fourth leading cause of cancer-related death (Shike et al, 1990). In 2007 colorectal cancer accounted for 17.1 deaths per 100000 persons in the United Kingdom (UK Bowel Cancer Statistics, 2009). Despite recent advances, the prognosis of patients with advanced and metastatic colorectal cancer remains poor. Targeting tumour metabolism for cancer therapy is a rapidly developing area (Pan and Mak, 2007). Early observations concerning the metabolic differences between cancer and normal cells were made by Otto Warburg, who showed that cancer cells are inherently dependent on glycolysis for production of chemical energy (Warburg, 1956). There is now mounting evidence that this increased glycolysis results from the influence of multiple molecular pathways, including adaptive responses to the hypoxic tumour microenvironment, oncogenic signalling, and mitochondrial dysfunction (Gatenby and Gillies, 2004; Gillies and Gatenby, 2007; Wu et al, 2007). The glycolytic phenotype offers growth advantages to cancer cells by resisting apoptosis, and facilitating tumour spread and metastasis (Yeluri et al, 2009).

A key regulator of cellular metabolism is pyruvate dehydrogenase (PDH). Pyruvate dehydrogenase converts pyruvate, produced from glycolysis, to acetyl-CoA, which is oxidised in the

*Correspondence: Dr BM Madhok; E-mail: umbm@leeds.ac.uk Revised 23 March 20I0; accepted 26 April 2010; published online 18 May 2010 tricarboxylic acid cycle within mitochondria. Pyruvate dehydrogenase activity is tightly regulated by inhibitory phosphorylation by pyruvate dehydrogenase kinase (PDK). Phosphorylation occurs on the E1 $\alpha$ sub-unit of PDH (PDHE1 $\alpha$ ) at three sites: $\operatorname{Ser}^{232}, \mathrm{Ser}^{293}$, and $\operatorname{Ser}^{300}$ (Rardin et al, 2009). Dichloroacetate (DCA) is an inhibitor of all the four isoenzymes of $\operatorname{PDK}(1-4)$ (Stacpoole, 1989), and has recently been shown to reduce growth of lung, endometrial, and breast cancer cell lines (Bonnet et al, 2007; Wong et al, 2008; Sun et al, 2009). It has been reported to reduce growth of these cancer cells mainly by reducing inhibitory phosphorylation of $\mathrm{PDH}$, thereby promoting mitochondrial oxidative phosphorylation and inducing apoptosis through mitochondrial, NFAT-Kv 1.5, and p53 upregulated modulator of apoptosis (PUMA)-mediated pathways.

Colorectal cancer cells have been found to undergo increased glycolysis ( $\mathrm{Bi}$ et al, 2006), and the tumour microenvironment has been found to be hypoxic and acidotic, mainly due to poorly developed blood supply (Dewhirst et al, 1989; Milosevic et al, 2004). We have previously shown that this is especially true for the more aggressive phenotype (Thorn et al, 2009), and expression of the important markers of hypoxia is increased in colorectal cancer especially at the invasive margin (Rajaganeshan et al, 2008, 2009). The purpose of this study was to investigate the effects of DCA on the growth of colorectal cancer cells in an attempt to examine PDK inhibition as a novel therapeutic strategy against colorectal cancer. 


\section{MATERIALS AND METHODS}

\section{Cell cultures}

All cell lines were purchased from American Type Culture Collection (Manassas, VA, USA) or European Collection of Cell Cultures (Salisbury, Wiltshire, UK): HB2 (breast epithelial cells of non-cancer origin), 293 (epithelial cells from human embryo kidney), HT29 (welldifferentiated primary colorectal adenocarcinoma), SW480 (poorly differentiated primary colorectal adenocarcinoma), and LoVo (metastatic left supraclavicular lymph node from colorectal adenocarcinoma). 293 and HB2 cells were maintained in DMEM medium, HT29 and SW480 in RPMI 1640 medium, and LoVo in F12 medium (all from Invitrogen, Carlsbad, CA, USA), supplemented with $10 \%$ fetal calf serum, in a $37^{\circ} \mathrm{C}, 5 \% \mathrm{CO}_{2}$ humidified incubator. For experiments under hypoxic conditions, we incubated cells in a humidified, hypoxic incubator $\left(1 \% \mathrm{O}_{2}, 5 \% \mathrm{CO}_{2}, 94 \% \mathrm{~N}_{2}, 37^{\circ} \mathrm{C}\right)$. Sodium dichloroacetate (Specials Lab, Prudhoe, UK) was donated by the Pharmacy Department at St. James's University Hospital, Leeds, UK.

\section{MTT assays}

Cells $\left(1 \times 10^{4}\right)$ per well were seeded in 96 -well tissue culture plates. After overnight incubation, we replaced media with fresh media containing increasing doses of DCA $(0,10,15,20,30,50$, and $100 \mathrm{~mm}$ ). After 24 and $48 \mathrm{~h}$ of incubation, we performed MTT assay by replacing the media with $50 \mu \mathrm{l}$ of $1 \mathrm{mg} \mathrm{ml}^{-1}$ MTT solution and the plates were incubated in the dark for $3 \mathrm{~h}$. MTT solution was then removed and the dark blue formazan precipitates were dissolved in $100 \mu \mathrm{l}$ of propan-1-ol. Optical density was measured using microplate reader (Opsys MR; Dynex Technologies Ltd, Worthing, West Sussex, UK) at $570 \mathrm{~nm}$.

\section{Annexin V and 7-AAD assays}

Cells were seeded in $25 \mathrm{~cm}^{2}$ tissue culture flasks and incubated overnight in standard conditions. Media was replaced with fresh media containing a range of doses of DCA $(0,10,20$, and $50 \mathrm{~mm})$. Flow cytometric analysis was performed after 24 and $48 \mathrm{~h}$ of incubation. Cells were washed twice with cold PBS and resuspended in $1 \times$ binding buffer (BD Bioscience, Franklin Lakes, NJ, USA) at $5 \times 10^{6}$ cells per ml. $100 \mu$ l of solution $\left(5 \times 10^{5}\right.$ cells $)$ was transferred to $5 \mathrm{ml}$ culture tubes. These cells were stained with $5 \mu \mathrm{l}$ annexin V-FITC and $10 \mu \mathrm{l}$ 7-AAD (BD Bioscience), gently vortexed, and incubated at ambient temperature for $15 \mathrm{~min}$ in dark. Following this $400 \mu \mathrm{l} 1 \times$ binding buffer was added to each tube and analysed within an hour on LSR II flow cytometer (BD Bioscience).

\section{Propidium iodide assays}

Cells were propagated as mentioned for the apoptosis assay. Dichloroacetate $(50 \mathrm{~mm}$ ) was used and compared to vehicle control. After harvesting, we resuspended cells in $350 \mu \mathrm{l}$ of PBS at a concentration of $0.5-1.0 \times 10^{6}$ cells per ml. $100 \mu \mathrm{l}$ of $0.25 \mathrm{mg} \mathrm{ml}^{-1}$ propidium iodide (PI)/5\% Triton (Sigma, St Louis, MO, USA) was added to the cell suspension. $50 \mu \mathrm{l}$ of $1 \mathrm{mg} \mathrm{ml}^{-1}$ ribonuclease A (Sigma) was then added. Sample tubes were thoroughly vortexed and incubated for $10 \mathrm{~min}$ in the dark at room temperature. Flow cytometry was performed on LSR II flow cytometer (BD Bioscience) and data were analysed using FlowJo software (FlowJo, Ashland, OR, USA).

\section{Lactate measurements}

Lactate measurements in growth media were performed by the chemical pathology department at the General Infirmary, Leeds Teaching Hospitals NHS Trust. Cells were incubated in $25 \mathrm{~cm}^{2}$ flasks overnight in normoxia. Media was replaced next day with a range of doses of DCA $(0,10,20$, and $50 \mathrm{mM})$. After $48 \mathrm{~h}$ of incubation, we collected $2 \mathrm{ml}$ of media in fluoride tubes and transferred immediately to the chemical pathology laboratory. The tubes were maintained on ice during the transfer. Lactate levels were measured using an automated analyser (Advia 1200 Chemistry system; Siemens Healthcare Diagnostics, Camberley, Surrey, UK).

\section{TMRM assays}

Cells were treated with DCA as described for the apoptosis assay. After 24 and $48 \mathrm{~h}$ of incubation, we washed cells in PBS, and suspended $1 \times 10^{6}$ cells per ml in Hank's buffered salt solution with $50 \mathrm{nM}$ tetramethylrhodamine methyl ester (TMRM) (Invitrogen). $100 \mu \mathrm{l}$ of the cell suspension $\left(1 \times 10^{5}\right.$ cells per well) was transferred to opaque 96 -well plates, incubated for $30 \mathrm{~min}$, and fluorescence was measured at $530 / 620 \mathrm{~nm}$ at $37^{\circ} \mathrm{C}$ using a plate reader (Mithras LB 40; Berthold Technologies, Bad, Wildbad, Germany).

\section{Western blotting}

Cells were treated with DCA as described above. After $8 \mathrm{~h}$ of treatment, we extracted proteins from cells in Laemmli buffer $(2 \%$ SDS, $10 \%$ glycerol, $0.7 \%$ 2-mercaptoethanol, $0.05 \%$ bromophenol blue, and $0.5 \mathrm{M}$ Tris-HCl). Lysates were resolved by electrophoresis on NuPAGE Novex 12\% Bis-Tris gels (Invitrogen) in MOPS-SDS running buffer (Invitrogen). Proteins were transferred to a polyvinylidene fluoride membrane (GE Healthcare, Chalford St Giles, Bucks, UK). The membrane was blocked for $1 \mathrm{~h}$ at ambient temperature in $5 \%$ skimmed milk in TBS-T (Tris-buffered saline with $0.1 \%$ Tween). The membrane was then probed with primary antibodies in $1 \%$ skimmed milk in TBS-T for $90 \mathrm{~min}$, washed in TBS-T, and then probed with the appropriate horseradish peroxidase (HRP)-conjugated secondary antibody for $60 \mathrm{~min}$. Primary antibodies rabbit polyclonal phosphodetect anti-PDH-E1 $\alpha\left(\mathrm{pSer}^{293}\right)$, 1:500 (AP1062; EMD Chemicals, Darmstadt, Germany), and mouse monoclonal anti-PDHE1 $\alpha, 1: 500$ (459400; Invitrogen). Secondary antibodies anti-rabbit or anti-mouse HRP conjugates, $1: 1000$ (Dako, Glostrup, Denmark). Proteins were visualised with Supersignal West Pico or Femto chemiluminescent substrate (Pierce Biotechnology, Rockford, IL, USA) and the Chemidoc XRS system (Bio-Rad, Hercules, CA, USA). $\beta$-Actin was used as a loading control.

\section{Statistical analyses}

Flow cytometry data were acquired using specific software, BD FACSDiva 6.0 and FlowJo software. Statistical analyses were performed using SPSS for Windows (SPSS version 15.0, Chicago, IL, USA). Differences between DCA-treated and vehicle control groups were assessed using the Mann-Whitney $U$-test and the $95 \%$ confidence intervals of the difference in means between the two groups. A $P$-value of less than 0.05 was considered to be statistically significant. Data are represented as mean from at least three independent experiments and error bars represent standard deviation of mean.

\section{RESULTS}

\section{DCA reduces cancer cell proliferation and the effect is similar in normoxia and hypoxia}

First, we wished to determine if treatment with DCA inhibited cellular proliferation and whether there would be a differential response in cancer and non-cancerous cells in normoxic and hypoxic conditions. With respect to hypoxia, our hypothesis was that influence of DCA would be particularly potent with oxygen levels that are insufficient to support additional oxidative phosphorylation. All cell lines (HB2, 293, HT29, SW480, and LoVo) were treated with a range of doses of DCA for $24-48 \mathrm{~h}$ in normoxic and hypoxic conditions. Relative cell numbers were assessed using MTT assays. 
Treatment with increasing doses of DCA reduced cellular proliferation in a dose-dependent manner (Figure 1A-D). Contrary to our expectation, the profiles of reduced cell growth were similar in hypoxia and normoxia. At 24 and $48 \mathrm{~h}$, up to $20 \mathrm{~mm}$ DCA did not affect the growth of cultures of the non-cancerous cells, HB2 and 293. However, $20 \mathrm{~mm}$ DCA significantly reduced growth of cultures of all three colorectal cancer cell lines $(P \leqslant 0.009)$. The effect of DCA was greater on the poorly differentiated SW480 cells and the metastatic LoVo cells than the well-differentiated HT29 cells. The growth of cultures of LoVo cells treated with $20 \mathrm{~mm}$ DCA was reduced by up to $40 \%$ compared to cells treated with vehicle control. Because there was relatively little difference in the reduction of growth of cultures treated with DCA in hypoxic and normoxic conditions, further experiments were performed only in normoxia.

\section{DCA promotes apoptosis in cancer cells sparing non-cancerous cells}

Next, we wished to investigate whether the reduced growth of cultures on treatment with DCA was associated with induction of apoptosis. Cells were treated with range of doses of DCA $(0,10,20$, and $50 \mathrm{~mm}$ ) for 24 and $48 \mathrm{~h}$, and the proportion of cells undergoing apoptosis was assessed by detecting membrane phosphatidylserine with annexin V-FITC. Cells were stained with annexin V-FITC and vital dye 7-AAD, and analysed using flow cytometry. There was a dose-dependent induction of apoptosis in the cancer cell lines after 24 and $48 \mathrm{~h}$ of treatment, with little, if any, apoptosis induced in the non-cancerous cells (Figure $2 \mathrm{~A}$ and $\mathrm{B}$ ). The greatest effect was observed in the metastatic LoVo cells; $50 \mathrm{~mm}$ DCA caused a ten-fold increase in the proportion of apoptotic cells after $48 \mathrm{~h}$, whereas there was a seven- and five-fold increase in HT29 and SW480 cells, respectively. Increase in the mean percentage of total apoptotic cells with $50 \mathrm{~mm}$ DCA was: 2.8 (95\% CI: 2-3) in HT29 cells, 3.5 (95\% CI: $2-5)$ in SW480 cells, and 21 (95\% CI: 8-34) in LoVo cells. There was minimal apoptosis induced in the 293 cells
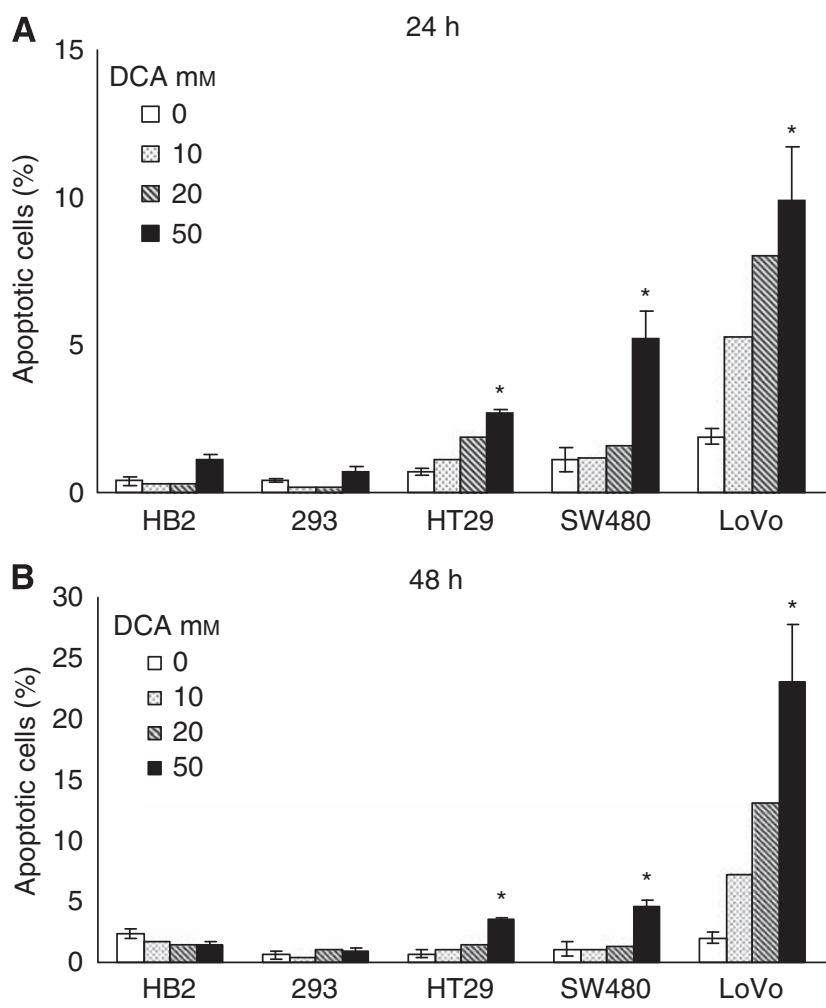

Figure 2 Dichloroacetate induced a dose-dependent increase in percentage of the apoptotic population in the cancer cells with minimal apoptosis in the non-cancerous cells. Cells were treated with doses of DCA for $24 \mathrm{~h}(\mathbf{A})$ and $48 \mathrm{~h}(\mathbf{B})$, stained with annexin V-FITC and 7-AAD, and analysed with flow cytometry. Data points represent the mean $( \pm$ s.d.) of three independent experiments for 0 and $50 \mathrm{~mm}$ DCA (* - significant difference relative to control).
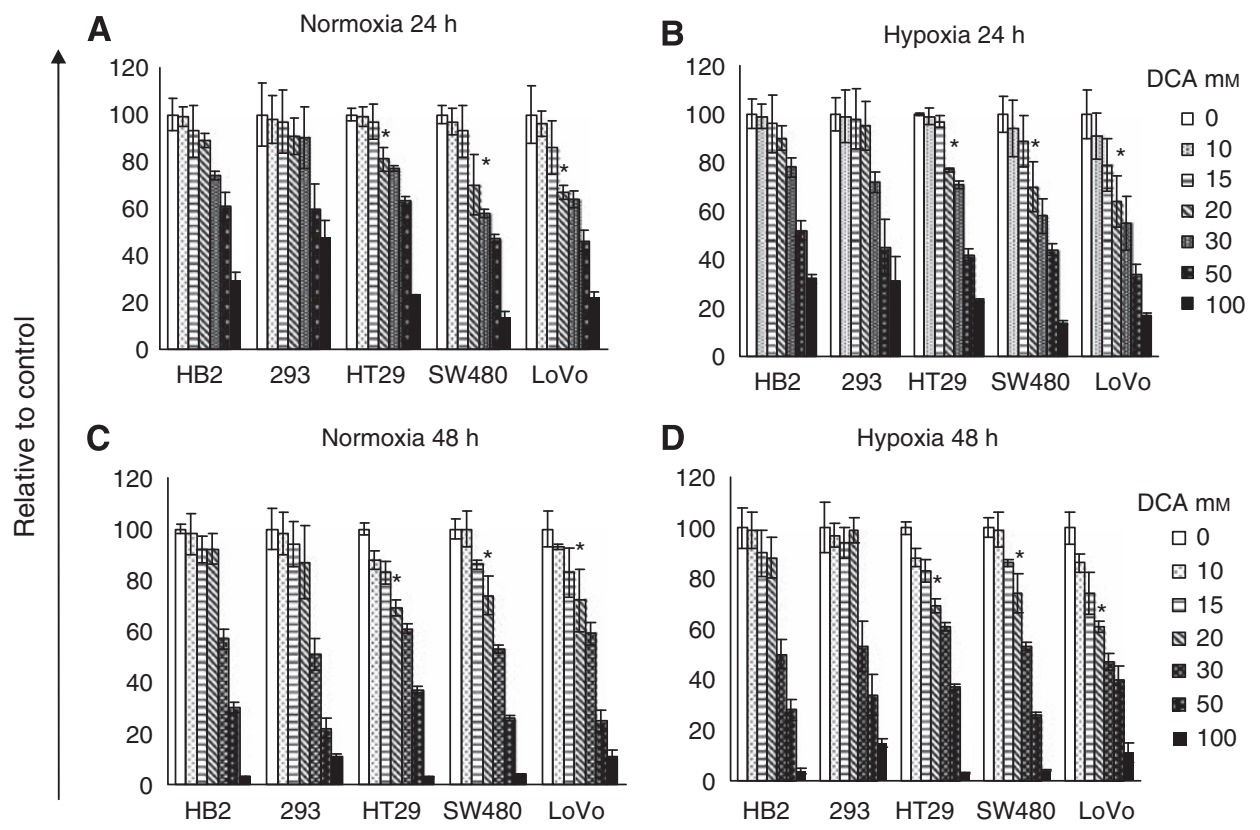

Figure I Dichloroacetate $(20 \mathrm{~mm})$ did not significantly reduce growth of cultures of the non-cancerous 293 and HB2 cells but caused a significant reduction in growth of cultures of all the colorectal cancer cells $(* P \leqslant 0.009)$. Cells were treated with various doses of DCA or vehicle control in normoxia $(\mathbf{A}$ and $\mathbf{C})$ or hypoxia (B and $\mathbf{D})$, and the relative number of viable cells was assessed at $24 \mathrm{~h}(\mathbf{A}$ and $\mathbf{B})$ and $48 \mathrm{~h}(\mathbf{C}$ and $\mathbf{D})$ using $\mathrm{MTT}$ assay. Data are expressed as percentage of control $\left(0 \mathrm{mM}\right.$ dose) $\left(^{*}-\right.$ significant difference relative to control - white bar $\left.(0 \mathrm{~mm})\right)$. 
even with $50 \mathrm{~mm}$ DCA, 0.2 (95\% CI: -0.2 to 0.6 ). In HB2 cells, there was a nonsignificant decrease in the percentage of apoptotic cells on treatment with $50 \mathrm{~mm}$ DCA, -0.9 (95\% CI: -2.2 to 0.4 ).

\section{DCA induces $G_{2}$ phase arrest in colorectal cancer cells but has no effect on cell-cycle profile of non-cancerous 293 cells}

We also wished to examine whether the reduction in growth of cultures on treatment with DCA was associated with induction of growth arrest. Cells were treated with $50 \mathrm{~mm}$ DCA for 24 or $48 \mathrm{~h}$, and cell-cycle profiles were analysed using flow cytometric assessment of DNA content after PI staining. Dichloroacetate treatment caused changes in the cell-cycle profiles of all the cancer cells but did not affect the non-cancerous cells. The changes in cell-cycle profile were detectable after $24 \mathrm{~h}$ of treatment, and were persistent at $48 \mathrm{~h}$ (Figure $3 \mathrm{~A}$ and $\mathrm{B}$ ).

After $48 \mathrm{~h}$ of treatment with $50 \mathrm{~mm}$ DCA, there was an eight-fold increase in the cells in $\mathrm{G}_{2}$ phase in HT29 and SW480 cells, and three-fold increase in LoVo cells. Increase in the mean percentage of all cancer cells in $\mathrm{G}_{2}$ phase was: 21 (95\% CI: 13 - 30) for HT29, 19 (95\% CI: $13-24)$ for SW 480 cells, and 14 (95\% CI: $10-21)$ for LoVo cells; whereas there was no difference in the 293 cells, 1 (95\% CI: -4 to 7 ), and HB2 cells, -0.3 (95\% CI: -9 to 9 ). There was a corresponding decrease in cells in $\mathrm{G}_{0} / \mathrm{G}_{1}$ phase in all cancer cell lines. Intriguingly, in HT29 cells there was a small decrease, but in SW480 and LoVo cells there was a significant increase in the
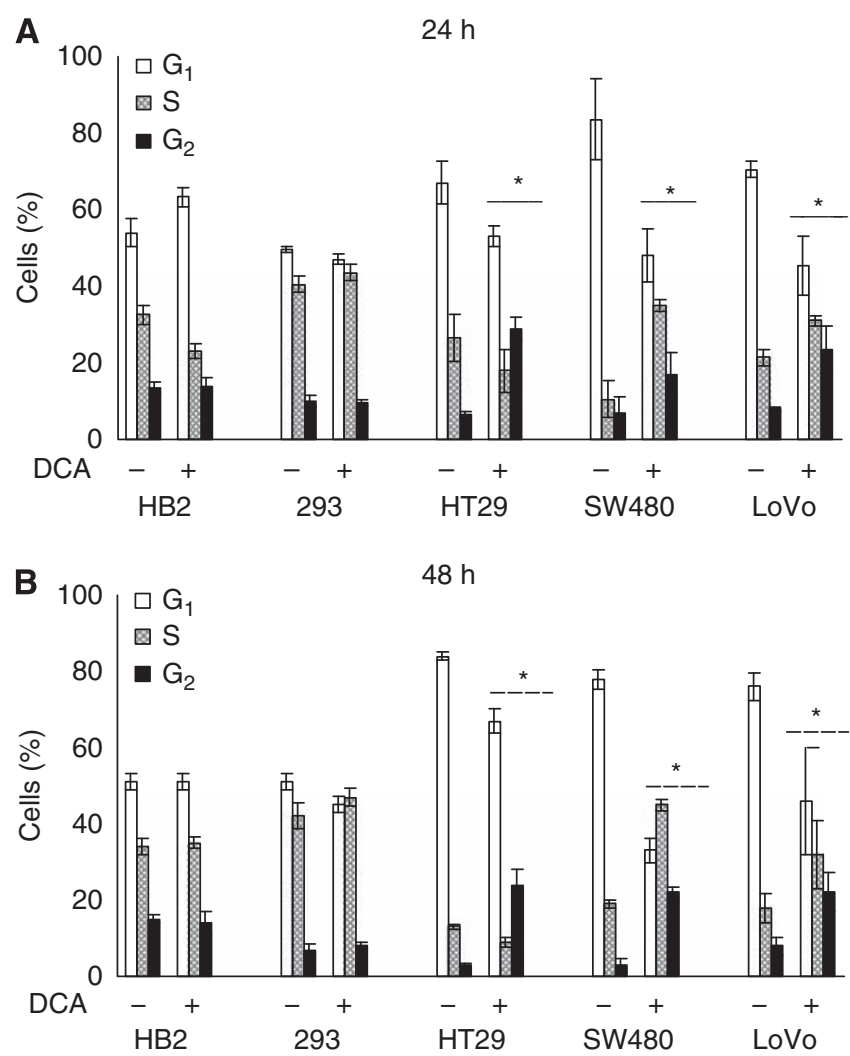

Figure 3 Dichloroacetate induced $\mathrm{G}_{2}$ phase arrest in colorectal cancer cells with no effect on cell-cycle profiles of non-cancerous cells; 293 and HB2. Cells were treated with $50 \mathrm{~mm}$ DCA or vehicle control for $24 \mathrm{~h}(\mathbf{A})$ and $48 \mathrm{~h}(\mathbf{B})$, stained with $\mathrm{Pl}$, and analysed with flow cytometry. For analyses of statistical significances, we compared mean proportion of cells in each phase of cell cycle $\left(G_{1}, S\right.$, and $\left.G_{2}\right)$ in DCA-treated cells to mean proportion of cells in the respective phases in untreated cells (* - significant difference relative to control). proportion of cells considered to be in the $\mathrm{S}$ phase (see Discussion section). The cell-cycle profile of 293 and HB2 cells changed minimally on treatment with DCA.

\section{DCA reduces extracellular lactate levels in growth media}

To establish whether the changes in growth and apoptosis induced by DCA correlated with reduced glycolysis, we measured lactate levels in growth media. Lactic acid is the end product of glycolysis. If DCA were inducing mitochondrial oxidative phosphorylation, pyruvate would be decarboxylated to acetyl-CoA and not reduced to lactate, hence lactate levels in the growth media would decrease. Lactate levels in growth media of all cell lines were measured after $48 \mathrm{~h}$ of treatment with a range of doses of DCA (Figure 4). Lactate levels were determined with an auto-analyser that is used routinely for biochemical measurement of lactate levels; the assays are based on a colorimetric reaction catalysed by lactate oxidase. Treatment with DCA reduced extracellular lactate levels in growth media in a dose-dependent manner in all the cancer and non-cancerous cell lines.

\section{DCA depolarises the intrinsic mitochondrial membrane in colorectal cancer cells but not in non-cancerous cells}

To verify if the induction of apoptosis in cancer cells on treatment with DCA was associated with promotion of mitochondrial oxidative phosphorylation, we measured the intrinsic mitochondrial membrane potential $(\Delta \Psi \mathrm{m})$. Escalation of mitochondrial respiration would reactivate the electron transport chain and reduce the hyperpolarised $\Delta \Psi \mathrm{m}$ in cancer cells. Cells were treated with doses of DCA for 24 and $48 \mathrm{~h}$ and stained with the dye TMRM, which allows fluorescent measurement of $\Delta \Psi \mathrm{m}$.

As with previous experiments, the effect of DCA was apparent after $24 \mathrm{~h}$ of treatment and persisted at $48 \mathrm{~h}$ (Figure 5A and B). Dichloroacetate treatment reduced the hyperpolarised $\Delta \Psi \mathrm{m}$ in all the cancer cells in a dose-dependent manner. Dichloroacetate did not have any effect on $\Delta \Psi \mathrm{m}$ of the non-cancerous HB2 cells, whereas, surprisingly the $\Delta \Psi \mathrm{m}$ of the non-cancerous 293 cells increased in a dose-dependent manner. At $24 \mathrm{~h}$ of treatment, $50 \mathrm{~mm}$ DCA significantly reduced $\Delta \Psi \mathrm{m}$ in all cancer cells; however, in LoVo cells there was a significant reduction even with $20 \mathrm{~mm}$ DCA (Figure 5A, $P=0.02$ ). In the non-cancerous 293 cells, there was a trend towards increase in $\triangle \Psi \mathrm{m}$ on DCA treatment, although this was not statistically significant $(P=0.08)$. At $48 \mathrm{~h}$ of treatment, there was significant reduction of $\Delta \Psi \mathrm{m}$ in all cancer cells and increase in the 293 cells, with $20-50 \mathrm{~mm}$ DCA (Figure 5B, $P \leqslant 0.04$ ).

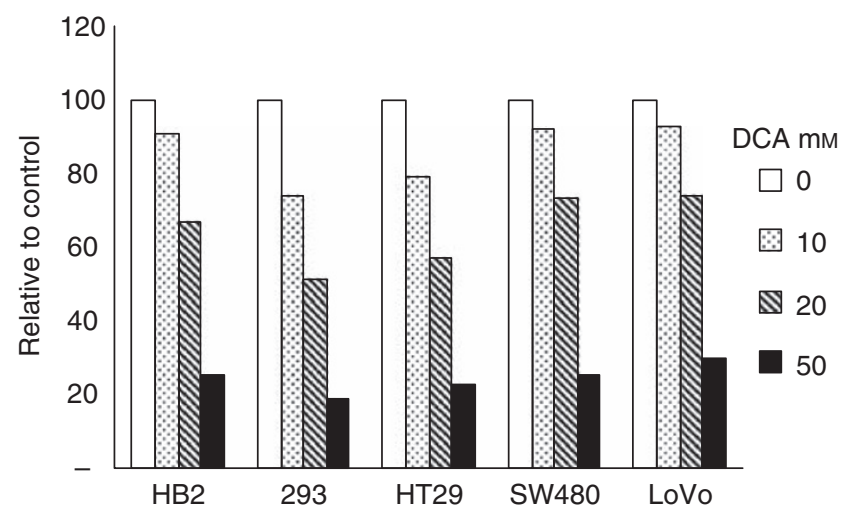

Figure 4 Dichloroacetate reduced lactate levels in growth media in a dose-dependent manner in both cancer and non-cancerous cells. Cells were treated with range of doses of DCA for $48 \mathrm{~h}$, and extracellular lactate levels were measured in the growth media using an auto-analyser. Results are expressed as relative of control. 

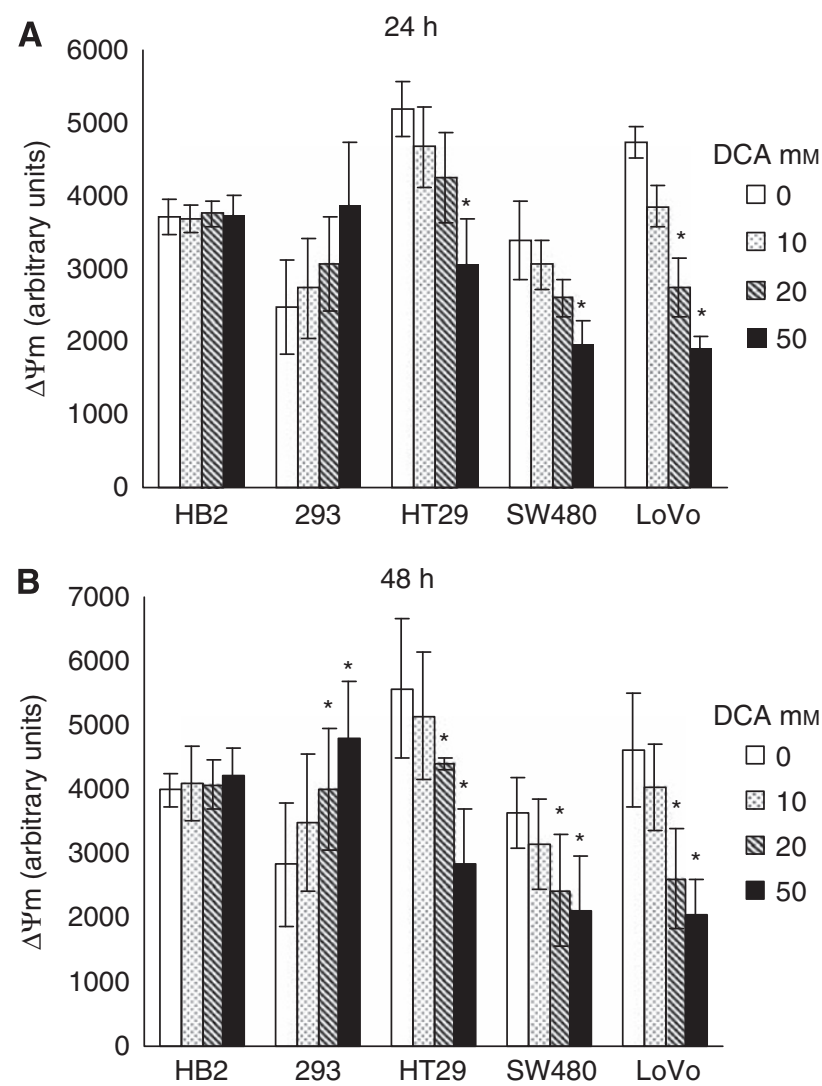

Figure 5 Dichloroacetate treatment reduced the intrinsic mitochondrial membrane potential $(\Delta \Psi \mathrm{m})$ in all cancer cells, increased $\Delta \Psi \mathrm{m}$ in non-cancerous 293 cells, and had no effect on $\Delta \Psi \mathrm{m}$ in non-cancerous HB2 cells. Cells were treated with doses of DCA for $24 \mathrm{~h}(\mathbf{A})$ and $48 \mathrm{~h}(\mathbf{B})$, stained with TMRM, and fluorescence was measured at 530/620 nm at $37^{\circ} \mathrm{C}$ (* - significant difference relative to control).

\section{DCA treatment leads to dephosphorylation of the PDHE1 $\alpha$ sub-unit}

DCA is thought to inhibit all four isoenzymes of PDK, and hence reduce phosphorylation of the $\mathrm{PDHE} 1 \alpha$ sub-unit, leading to, in turn, activation of the PDH complex. To verify if the dephosphorylation of PDHE $1 \alpha$ was occurring with DCA treatment in the cell lines used, we used western blot analyses on lysates of DCA-treated and untreated cells. In all cell lines, treatment with $20 \mathrm{~mm}$ DCA for $8 \mathrm{~h}$ caused a dramatic reduction in signal for phosphorylation at the $\mathrm{pSer}^{293}$ site, but no change was detected in the levels of total PDHE1 $\alpha$ (Figure 6). Phospho-specific antibodies for the other two phosphorylation sites, $\operatorname{Ser}^{232}$ and $\mathrm{Ser}^{300}$, are not yet commercially available.

\section{DISCUSSION}

\section{Differential effects of DCA on growth of cancer and non-cancerous cells}

We have shown that DCA induces a dose-dependent reduction in growth of in vitro cultures of colorectal cancer cells and non-cancerous cells. However, the cancer cells were more sensitive to DCA, with a dose of $20 \mathrm{~mm}$ causing a significant inhibition of cancer cell growth, but having little effect on the non-cancerous cells. We have shown that the components of this differential effect are the following: a potent induction of apoptosis and cell-cycle arrest in cancer cells, but not in the non-cancerous cells.

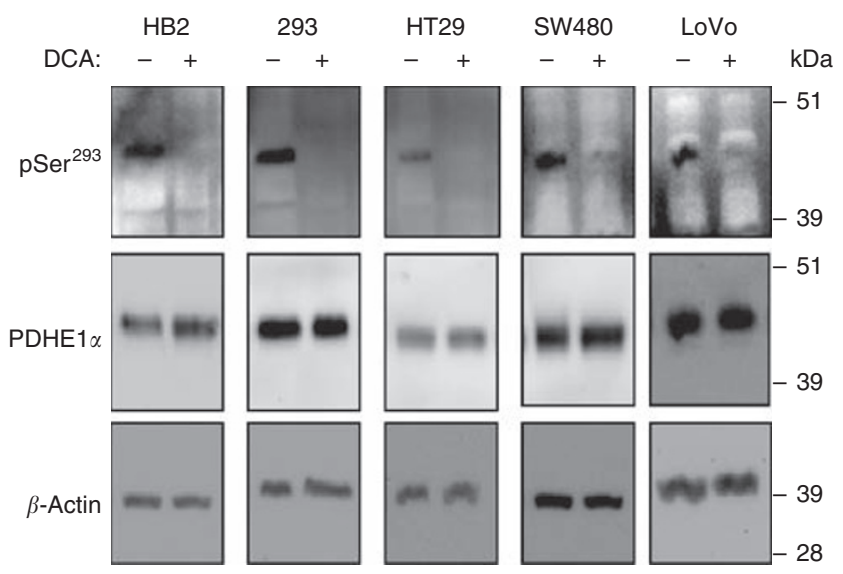

Figure 6 Dichloroacetate treatment reduced phosphorylation of PDHEI $\alpha$ at pSer ${ }^{293}$ site with no effect on the levels of total PDHEI $\alpha$ in all the cell lines investigated. Whole-cell lysates were prepared after treating cells with $20 \mathrm{~mm}$ DCA for $8 \mathrm{~h}$ and from untreated cells, and western blot analyses were performed.

These conclusions support a simple model of differential sensitivity to DCA. However, some data require further discussion. First, $50 \mathrm{~mm}$ DCA reduced growth of cultures of the non-cancerous 293 and HB2 cells, yet no increase in apoptotic cells or change in cell-cycle profile of these cells was observed. A possible explanation for these findings could be that this dose of DCA led to a slower transit of these non-cancerous cells through all stages of the cell cycle, without changing the relative proportions within each stage. Second, our results indicate that DCA induced $\mathrm{G}_{2}$ arrest in colorectal cancer cells. This is in contrast to previous studies, which have shown $G_{1}$ arrest or no change on cell-cycle profile with DCA treatment (Cao et al, 2008; Wong et al, 2008). Wong et al (2008) showed increased expression of PUMA in all the endometrial cancer cell lines that had an apoptotic response to DCA, and concluded that this p53 activation led to $G_{1}$ arrest. However, colorectal cancer cells in our study arrested in $G_{2}$ phase on treatment with DCA, and we did not find any induction of p53 by DCA in our colorectal cancer cell lines (data not shown). Intriguingly, Cao et al (2008) found that the combination of DCA and radiotherapy arrested prostate cancer cells in $G_{2}$ phase, although DCA on its own did not affect cell-cycle profile. Third, in SW480 and LoVo cells, DCA treatment resulted in an increase in the proportion of cells considered to be in the $\mathrm{S}$ phase. This suggests an increase in proliferation as well as induction of apoptosis. A similar finding was reported by Wong et al (2008) in one of several endometrial cancer cells tested. An alternative explanation is that a proportion of the cells observed to be in 'S phase' after DCA treatment of the cancer cell lines actually represent apoptotic cells in the 'sub- $\mathrm{G}_{2}$ ' region, as has been reported previously in lymphoma cells (Klucar and Al-Rubeai, 1997).

\section{Changes in cellular metabolism with DCA treatment}

DCA appeared to suppress lactic acid production from pyruvate in both cancer and non-cancerous cells. In addition, treatment with DCA led to dephosphorylation of PDHE1 $\alpha$, and hence activation of $\mathrm{PDH}$ in all the cell lines investigated. Hence, the basis of DCA's differential effect on cancer and non-cancerous cells may reside in its influence on mitochondrial function. Treatment with DCA reduced the high $\Delta \Psi \mathrm{m}$ of all cancer cells but not of the noncancerous cells. This suggests that DCA, by inhibiting PDK and hence activating $\mathrm{PDH}$, promotes mitochondrial respiration that leads to depolarisation of the intrinsic mitochondrial membrane, 
and induces apoptosis by the proximal mitochondrial pathway as described in the previous studies (Bonnet et al, 2007; Cao et al, 2008; Wong et al, 2008). Induction of apoptosis and changes in mitochondrial function were most pronounced in the highly invasive and metastatic LoVo cells than the less invasive HT29 and SW480 cells. This could have clinical implications for the treatment of metastatic colorectal cancer, as it is usually the highly invasive metastatic cancers that are most resistant to conventional chemotherapy, and which may be most sensitive to PDK inhibition. In support of this, a recent study reported that the colorectal tumours resistant to 5-fluorouracil are more likely to have upregulated glycolysis, and hence more amenable to therapy targeting cancer metabolism (Shin et al, 2009). In this regard, our results contrast the findings of Wong et al (2008), who found highly invasive endometrial cancer cells to be most resistant to DCA treatment.

\section{PDK inhibition as cancer therapy against colorectal cancer}

We found doses of 20-50 mM DCA gave differential responses between cancer and non-cancerous cells. Thus, potential therapeutic DCA doses would be between 20 and $50 \mathrm{~mm}$. In addition, a recent study reported that the $\mathrm{IC}_{50}$ of DCA for breast cancer cells to be between 20 and $30 \mathrm{~mm}$ (Ko and Allalunis-Turner, 2009). This is in contrast to previous studies that have reported DCA to reduce proliferation and induce apoptosis in cancer cells with doses as low as 0.5-10 mM (Bonnet et al, 2007; Wong et al, 2008; Sun et al, 2009). Dichloroacetate has been found to be relatively safe in humans when used for treatment of lactic acidosis (Stacpoole et al, 2003). The main side effects with up to $100 \mathrm{mg} \mathrm{kg}^{-1}$ DCA are on the nervous system and the liver, causing mild sedation or

\section{REFERENCES}

Bi X, Lin Q, Foo TW, Joshi S, You T, Shen HM, Ong CN, Cheah PY, Eu KW, Hew CL (2006) Proteomic analysis of colorectal cancer reveals alterations in metabolic pathways: mechanism of tumorigenesis. Mol Cell Proteomics 5: 1119-1130

Bonnet S, Archer SL, Allalunis-Turner J, Haromy A, Beaulieu C, Thompson R, Lee CT, Lopaschuk GD, Puttagunta L, Bonnet S, Harry G, Hashimoto K, Porter CJ, Andrade MA, Thebaud B, Michelakis ED (2007) A mitochondria-K+ channel axis is suppressed in cancer and its normalization promotes apoptosis and inhibits cancer growth. Cancer Cell 11: 37-51

Bowker-Kinley MM, Davis WI, Wu P, Harris RA, Popov KM (1998) Evidence for existence of tissue-specific regulation of the mammalian pyruvate dehydrogenase complex. Biochem J 329(Part 1): 191-196

Cao W, Yacoub S, Shiverick KT, Namiki K, Sakai Y, Porvasnik S, Urbanek C, Rosser CJ (2008) Dichloroacetate (DCA) sensitizes both wild-type and over expressing Bcl-2 prostate cancer cells in vitro to radiation. Prostate 68: $1223-1231$

Dewhirst MW, Tso CY, Oliver R, Gustafson CS, Secomb TW, Gross JF (1989) Morphologic and hemodynamic comparison of tumor and healing normal tissue microvasculature. Int J Radiat Oncol Biol Phys 17: 91 - 99

Gatenby RA, Gillies RJ (2004) Why do cancers have high aerobic glycolysis? Nat Rev Cancer 4: 891-899

Gillies RJ, Gatenby RA (2007) Adaptive landscapes and emergent phenotypes: why do cancers have high glycolysis? J Bioenerg Biomembr 39: $251-257$

Klucar J, Al-Rubeai M (1997) G2 cell cycle arrest and apoptosis are induced in Burkitt's lymphoma cells by the anticancer agent oracin. FEBS Lett 400: $127-130$

Ko L, Allalunis-Turner J (2009) Investigation on the mechanism of dichloroacetate (DCA) induced apoptosis in breast cancer. J Clin Oncol 27(Suppl 15): e14637

Michelakis ED, Webster L, Mackey JR (2008) Dichloroacetate (DCA) as a potential metabolic-targeting therapy for cancer. Br J Cancer 99: 989-994

Milosevic M, Fyles A, Hedley D, Hill R (2004) The human tumor microenvironment: invasive (needle) measurement of oxygen and interstitial fluid pressure. Semin Radiat Oncol 14: 249-258 drowsiness, reversible peripheral neuropathy, and mild asymptomatic elevation of serum transaminases reflecting hepatocellular damage (Stacpoole et al, 1998). In addition, recent studies reported that DCA effectively reduced tumour growth in clinically achievable doses both in vitro and in vivo (Bonnet et al, 2007; Sun et al, 2009). It was suggested that DCA could rapidly translate to earlyphase cancer clinical trials (Michelakis et al, 2008). However, the dose of DCA required to inhibit growth of colorectal cancer cells in our study is unlikely to be achieved clinically without causing significant side effects. The dose of DCA required to achieve the equivalent plasma concentrations in vivo would be about five to ten times than that used in clinical trials against lactic acidosis. It appears that the colorectal cancer cells used in our study are more resistant to DCA than lung, endometrial, and breast cancer cells. Intriguingly, Sun et al (2009) in their study on breast cancer cells found that DCA inhibited proliferation of cancer cells, but did not induce apoptosis or cell death. These results were markedly different to the effects of DCA observed on lung (Bonnet et al, 2007), endometrial (Wong et al, 2008), and colorectal cancer cells in our study. Thus, although DCA inhibits growth of a variety of cancer cells, the effect and the underlying mechanisms seem to be cell-type dependent. A likely explanation for these differential effects could be the difference in expression of the PDK isoenzymes in the cancer cells examined. Dichloroacetate is a non-specific inhibitor of PDK (Whitehouse and Randle, 1973), and has a different $K_{\mathrm{i}}$ for each of the four PDK isoenzymes (Bowker-Kinley et al, 1998). In addition, the four PDK isoenzymes are known to be differentially expressed in various tissues. Thus, there is a need to develop inhibitors to the individual PDK isoenzymes that should allow cancer cell-type-specific metabolic manipulation.
Pan JG, Mak TW (2007) Metabolic targeting as an anticancer strategy: dawn of a new era? Sci STKE 2007: e14

Rajaganeshan R, Prasad R, Guillou PJ, Poston G, Scott N, Jayne DG (2008) The role of hypoxia in recurrence following resection of Dukes' $\mathrm{B}$ colorectal cancer. Int J Colorectal Dis 23: 1049-1055

Rajaganeshan R, Prasad R, Guillou PJ, Scott N, Poston G, Jayne DG (2009) Expression patterns of hypoxic markers at the invasive margin of colorectal cancers and liver metastases. Eur J Surg Oncol 35(12): $1286-1294$

Rardin MJ, Wiley SE, Naviaux RK, Murphy AN, Dixon JE (2009) Monitoring phosphorylation of the pyruvate dehydrogenase complex. Anal Biochem 389: 157-164

Shike M, Winawer SJ, Greenwald PH, Bloch A, Hill MJ, Swaroop SV (1990) Primary prevention of colorectal cancer. The WHO Collaborating Centre for the Prevention of Colorectal Cancer. Bull World Health Organ 68: $377-385$

Shin YK, Yoo BC, Hong YS, Chang HJ, Jung KH, Jeong SY, Park JG (2009) Upregulation of glycolytic enzymes in proteins secreted from human colon cancer cells with 5-fluorouracil resistance. Electrophoresis 30: $2182-2192$

Stacpoole PW (1989) The pharmacology of dichloroacetate. Metabolism 38: $1124-1144$

Stacpoole PW, Henderson GN, Yan Z, James MO (1998) Clinical pharmacology and toxicology of dichloroacetate. Environ Health Perspect 106(Suppl 4): 989-994

Stacpoole PW, Nagaraja NV, Hutson AD (2003) Efficacy of dichloroacetate as a lactate-lowering drug. J Clin Pharmacol 43: 683-691

Sun RC, Fadia M, Dahlstrom JE, Parish CR, Board PG, Blackburn AC (2009) Reversal of the glycolytic phenotype by dichloroacetate inhibits metastatic breast cancer cell growth in vitro and in vivo. Breast Cancer Res Treat 120(1): 253-260

Thorn CC, Freeman TC, Scott N, Guillou PJ, Jayne DG (2009) Laser microdissection expression profiling of marginal edges of colorectal tumours reveals evidence of increased lactate metabolism in the aggressive phenotype. Gut 58: 404-412 
DCA promotes apoptosis in colon cancer cells BM Madhok et al

1752

UK Bowel Cancer Statistics (2009) http://info.cancerresearchuk.org/cancerstats/ types/bowel/

Warburg O (1956) On the origin of cancer cells. Science 123: 309-314

Whitehouse S, Randle PJ (1973) Activation of pyruvate dehydrogenase in perfused rat heart by dichloroacetate. Biochem J 134: $651-653$

Wong JY, Huggins GS, Debidda M, Munshi NC, De Vivo I (2008) Dichloroacetate induces apoptosis in endometrial cancer cells. Gynecol Oncol 109: 394-402
Wu M, Neilson A, Swift AL, Moran R, Tamagnine J, Parslow D, Armistead S, Lemire K, Orrell J, Teich J, Chomicz S, Ferrick DA (2007) Multiparameter metabolic analysis reveals a close link between attenuated mitochondrial bioenergetic function and enhanced glycolysis dependency in human tumor cells. Am J Physiol Cell Physiol 292: C125-C136

Yeluri S, Madhok B, Prasad KR, Quirke P, Jayne DG (2009) Cancer's craving for sugar: an opportunity for clinical exploitation. J Cancer Res Clin Oncol 135: $867-877$ 